\title{
Vision of Broadcasters towards the Role of Media Education and ethics in Saudi Arabia
}

\author{
Dr. Hanan A. Ashi*
}

\begin{abstract}
Media education is the process of utilization of communication in an optimal way to achieve the educational goals in the educational and media policy of the state. This study used interviews with 46 broadcasters from both genders of media professionals. The most important findings of this study are $67 \%$ of media professionals believe that the Ministry of Culture and Information is responsible for raising awareness of media and the non-application of media education in media practices is due to the weakness of official censorship. Best ways to improve the performance of the media are: the formation of ethics and legislation committees, activation of contact programs and establishing complaints. The most important recommendation is urging media professionals and educators to coordinate in planning the educational content that is presented to young people and the assessment of the materials addressed families and children.
\end{abstract}

\section{Introduction}

Visual media are the most pervasive in homes and reflect the social environment through symbols and images. They contribute to the socialization of citizens. Such materials are also a cultural force in society because of their active role in mental image creation and promotion as dramatic means.

Media scholars are concerned with studying visual media in terms of their influential presence in society. It is the study of what is being and what should exist. So they derive their topics and materials in their positions and events from the prevailing social and cultural environment. Such materials reflect the attributes and characteristics

\footnotetext{
* Associate Professor Faculty of Communication and Media, King Abdulaziz University
}

The Scientific Journal of Radio and Television Research - Issue 17 - January / June 2019537 
of the community including the issues, trends, values, traditions, norms and ideas making the visual media the leading generators and contemporary cultural connectors.

With the emergence of the information and communication revolution, the visual media have become one of the most dangerous means of socialization as they contribute to the upbringing of young people who spend most of their time before them. Out of this, calls have recently increased for the formulation of an Arabic media strategy based on a conscious vision which enables families to deal with the new world order whatever the variables and challenges posed in the framework of the concept of media education .

Thus, media education employs the means of communication in an optimal way in order to achieve the educational goals set forth in the educational and informational policy of the State. Therefore, it does not only affect students in schools, but its influence also gets to fathers, mothers, brothers and sisters in the family and to all members of society (Ashi, 2018).

Potter (Potter, 2010), referred to how media education had been dealt with as an issue in the design of curricula in institutions of learning, and then how to deal with it as an overlapping issue by parents and researchers. That is why the academic institutions have become interested in this concept and seek to design media education programs based on the emphasis on the transfer of important values of media education such as social responsibility and ethics.

Also in this regard the researcher "Lenny Hobbs" (Hobbs, 2011) emphasized the need to introduce courses in higher education stages to describe the relationship between communication and media studies as well as education in more depth.

It was therefore necessary to examine the nature of the role of media education and its impact on the broadcasters in the visual Saudi media sector. Under this growing trend to study the issues of media education, we find the results of one recent study showed that the design of an informative article that takes into account the nature of audiences and their needs, especially audiences of children, is not a priority for many channels in Spain. In contrast, the government channels and some regional channels are the only ones committed to 
the observance of these ethics (Ortiz; Ruiz \& Diaz, 2010).

\section{The Theoretical Framework of the Study: Social Responsibility Theory}

The idea of this concept is confirmed by Dennis McQuail who stated that the main foundations of this theory lie in that media are responsible for the community and to gain the trust of the public. They acquire their prestige through accuracy, credibility, objectivity and balance. Beyond this, there is the commitment to freedom considering ethical codes of conduct, laws, legislations and professional values to achieve the public interest (Baran \& Davis, 2011);( Ibrahim, 2011).

Social responsibility for television includes religious, political, socio-cultural support and activation of these principles in the media are achieved through declared and implicit regulations. The media laws and codes of conduct come among these subjects to the availability of freedom in society (Abdul Halim, 2012). Since this is a world trend, the managers of the German channel 2 stressed that promotion of the concept of media education and spreading awareness of it is the responsibility of broadcasters (ZDF, 2006).

The reasons for choosing this theory for this study are:

1. This study seeks to uncover the extent of awareness of the broadcasters of the media education, its dimensions and how far it is regarded in the production of media messages. This is consistent with the main dimensions of the theory which stresses the importance of the media performance criteria which constitutes the ethical and legal control governing the conduct of media.

2. Academicians see that media education programs based on the learning process as well as transfer of ethics and social responsibility, enables students to take more active roles in the acquisition of knowledge skills.

\section{Previous Studies}

Social responsibility and ethics in the past seventy years have been and still are important concepts. Most recent studies focus on the social responsibility and ethics of the electronic media (Basu, 2011). The results of some studies showed that media professional practices didn't fulfill the required role and there has been a threat to the 
plurality of views, especially in the light of the trend towards concentration of ownership. Scholars stressed that monopolies reduce the number of communicators who cover news stories locally and nationally in America and also showed that the independence of media in this way may end as they will protect only their owners with no regard to their social responsibility and ethics (Hollon, 2009), (Corneo, 2005).

1. Public broadcasting corporations must intervene strongly in the news coverage and focus on supplying the public with accurate information so that the democratic process is completed in the communities as the media do their social responsibilities (Ananya, 2011).

2. A study indicated that the solution that makes media fulfill their social responsibilities lies in that charters of honor be issued, as Spanish national channels signed the self-regulatory code of conduct for the protection of children's rights in viewing (San Román \& Montero, 2008).

3. Scholars suggested developing the theory to suit modern developments at political, socio-economic and technical levels by adding the concept of protection of media stakeholders to reach socially responsible editors (Cleary \& Adams-Bloom, 2009); (Singer, 2006).

By the end of the last century, several countries adopted the Advertising Self-Regulation (ASR) systems to establish some standards for the advertising quality and business ethics to avoid some moral problems in advertising. Recently a study by Feenstra \& Esteban (2017) focused on the Spanish ASR that was established in 1995 to study the functioning of the system and examine its achievements and the challenges that face it. The study was based on several interviews conducted with the Autocontrol (The Spanish Association for the Self-Regulation of Commercial Communication) members. The study showed that the Spanish Autocontrol proved that ASR can work efficiently to prevent some bad advertising manners and strengthen the principles of rigour, independence and participation. The study also showed that there are some challenges that face the Spanish Autocontrol such as the complexity of the procedures they follow and the need to improve the deliberative 
process for governing self-regulation (Feenstra \& Esteban, 2017).

In the same manner, broadcasting in Nigeria had been pluralized with the public service and business models in a study by Osazee-Odia \& Ije (2017). The study showed that the broadcasting policy in Nigeria, adopted by the National Broadcasting Commission (NBC), had played a vital role in the diversity of the offered programs format and genres to grab the attention of the audience in Nigeria. The NBC was responsible of providing the regularity framework and conforming the self-regulation in broadcasting stations. The study also proposed some recommendations such as the need of the comprehensive assessment of the broadcasting stations, studying the audience opinion for better knowledge and increasing the radio broadcasting especially in rural communities (Osazee-Odia \& Ijeh, 2017)..

In another study by Wu \& Lambert ( 2016), the main interest was on the impediments and obstructions to the journalistic ethics in Taiwans's media market. The aim of the study was to examine the threats to journalistic freedom and practice in Tawian by conducting in-depth interviews with 20 of the current and former media professionals. The study showed that some Taiwanese and foreign governments and commercial entities can form some pressure through funds on the media managers to air and publish slanted stories. The study also showed that the Taiwanese media is in bad need for new and strict media laws and policies to enforce the standards for journalistic ethics (Wu \& Lambert, 2016).

This study, conducted by Khalifa (2015), aims at identifying the attitudes of the media elites towards the ethical commitment of the major Palestinian news sites. The study was a descriptive research through which the researcher used a survey method. The majority of the population of the study consisted of 79 communicators . The study shows the Palestinian news sites have a low commitment to social responsibility with a percentage of $58.7 \%$, yet they kept the cultural identity of the Palestinians and didn't publish pictures that violate the public ethics. The responses in this concern were positive with a percentage of $70.1 \%$. The findings of the study also show that the Palestinian news sites have a low commitment to their legal responsibility with a percentage of $61.6 \%$. They violated this 
responsibility by showing violent pictures of child victims and victimizers. The findings of the study show the low percentage pertaining to the news sites commitment to the reliability, integrity and accuracy. They had weak commitment to the difference between reporting and expressing personal opinions. They also showed the news either with understatement or overstatement. The study shows that the political split between the Palestinian factions has a negative impact on the news sites and their commitment to the ethical code of the profession. The study shows also that the most prominent reasons for jumping the code of ethics of the profession is the political split among Palestinian factions, abidance to a political attitude, lack of training and finally lack of a binding law in force to regulate the online news in Palestine (Kalifa, 2015).

A study was conducted on the social responsibility of the Egyptian governmental and private satellite channels, as watched by the elites. The results showed an increase in the percentage of live programs in the channels and an intense interest in the dimensions of ethical responsibility of the programs towards the community, including respect towards the public's right to know by $34.7 \%$. Concerning caring about the public interests of the society, by $23.3 \%$, where the percent in private channels was higher than in the governmental ones. Protecting the religious and moral values of the community came by $21.1 \%$, respecting political principles of the community by $6 \%$ (Abdul Halim, 2012).

Results of a study aimed to identify the limits of professional freedom and responsibility in the performance of global satellite news networks and their impact on the direction of foreign audiences towards Arab issues showed that Western networks are biases against Arab issues (Hassan, 2008).

A study of the political influences of the Egyptian and Arab satellite channels in the context of social responsibility results indicated that $45.9 \%$ of the sample relied on the Egyptian and Arab satellite channels as the primary source for getting political news. Egyptian governmental channels came at 27.9\%. (Samir, 2008).

Another study aimed at addressing media ethics in private Arab satellite channels as seen by the Egyptian public to identify the 
features of the Egyptian public's vision on ethics of private Arab TV channels relying on the social responsibility theory showed the following findings: providing real news topped the motives of respondents behind viewing the private Arab channels by only $16.61 \%$, opening sensitive files and themes not dealt with by the rest of other channels by only $8.59 \%$, and Arab satellite channels working to provide a high degree of commitment to media ethics by only 9.12\% (Al Banna, 2008).

Another study dealt with the functional relationship nature between the communicator and the public in local Saudi media to identify how far the communicator seeks to establish a functional relationship with the public to provide media performance consistent with the standards of professional performance. The results of this study showed that the functional relationship between Saudi media communicators and the public is weak, inconsistent and communicators do not often seek to support the perceptions and needs of the public objectively (Al Subaihi, 2008).

In the light of the previous studies, the following points can be deduced:

1. Most of the studies on the Arab world focused on Egyptian broadcasters.

2. The scarcity of studies concerning the importance of the media education and ethics, particularly Saudi Arabia.

3. Lack of awareness of broadcasters regarding their responsibilities due to being uninformed of the media code of conduct. This is considered dangerous as commitment to the ethics and values of the society is the most important responsibility and this is the core of this study.

\section{The Study Problem and its Importance}

This study aims to identify the broadcasters' awareness of the media education and its application in the message production in observance of professional standards addressed to the family, especially children, applied on a sample of Jeddah media professionals.

\section{Question of the study:}


The main question of the study is: "What is the media professional's vision regarding the role of media education within the framework of the social responsibility theory?"

Subsidiary questions are:

1. Who is responsible for the media education deployment and development for broadcasters?

2. What is the extent of cooperation with educators in the production of messages?

3. What is the extent of compliance with media codes of conduct in message production?

4. What is the opinion of the broadcasters about the extent of the vulnerability of Saudi families and children towards negative values?

5. From the broadcasters' views is there an effective censorship in Saudi media materials containing negative values, which the family and the child are exposed to?

6. What is the extent of the commitment of Saudi media to media codes from the broadcasters' opinions?

7. What is the media professional nature of the assessment to his performance towards the family and the child?

8. What are the ideas and proposals, from the broadcasters' views, for raising awareness of the concepts of media education in the Saudi media sector in the framework of social responsibility theory ?

\section{Importance of the Study}

1. The increasing criticism directed to the negative role of broadcasters towards children.

2. The scarcity of Arab studies on media education, assuming that it could negatively affect Saudi families.

3. The controversy over the extent to which media organizations are committed to codes of conduct.

\section{The Study Objectives}

1. Determine the methods used by the communicator to assess his message before its transmission.

2. Determine how far the communicator is interested in his message contribution to the progress of society in the light of Islamic values. 
3. Determine the extent of interest in media policies application by the media corporations.

\section{Methodology of the Study}

This study is a descriptive analytical study that monitors the nature of broadcasters' awareness of media education, its application in their message production and their assessment of the nature of their role in the formation of the attitudes of the Saudi family. This study uses interviews with broadcasters in the audiovisual media, which is the appropriate approach for this study due to lack of information in the area.

\section{The Study Sample:}

It is an available purposive sample of 46 broadcasters of the two genders, including four from the audio media and 42 from the visual media. The sample represents the following private and governmental organizations: UTURN, Radio FM MBC, AA, Made in Saudi films, Saudi Broadcasting Corporation, W.M. Productions, Full Stop, Mix FM, Rotana, Libra Production, Al Magd Satellite Network, Jeddah Radio, Vision Films and Wed Films.

\section{Table (1)}

The sample characteristics of

\begin{tabular}{llll}
\hline Characteristics of the sample & \multicolumn{2}{l}{ Total } \\
\cline { 3 - 4 } & & Frequency & $\begin{array}{l}\text { Percentage } \\
(\%)\end{array}$ \\
\hline Gender & Males & 30 & $65.2 \%$ \\
& Females & 16 & $34.8 \%$ \\
Work & Broadcaster & 10 & $21.7 \%$ \\
& Presenter & 10 & $21.7 \%$ \\
& Program Preparer & 10 & $21.7 \%$ \\
& Producer & 5 & $10.9 \%$ \\
& Editor & 4 & $8.7 \%$ \\
\hline
\end{tabular}


Vision of Broadcasters Towards the Role of Media Education and ethics in Saudi Arabia

\begin{tabular}{llll}
\hline Characteristics of the sample & \multicolumn{2}{l}{ Total } \\
\cline { 2 - 4 } & Cameraman & 4 & $8.7 \%$ \\
& $\begin{array}{l}\text { Decoration \& Lighting } \\
\text { Technician }\end{array}$ & 3 & $6.6 \%$ \\
Specialization & Media Professional & 25 & $54.3 \%$ \\
& Non-Media Professional & 21 & $45.7 \%$ \\
\hline
\end{tabular}

Table 1 shows the sample attributes based on the interviews with the following characteristics:

- The percentage of males in the sample is higher than that of females. It was $65.2 \%$ versus $34.8 \%$.

- The percentage among the sample was the same for three occupations: broadcaster, director and program preparer at $21.7 \%$ and broadcaster by $10.9 \%$.

- Only $54.3 \%$ of respondents were specialists in the Media profession while $45.7 \%$ were not.

\section{Data Collection Tool:}

In depth interview was used to measure the broadcasters' visions regarding the role of the media education in forming the awareness of the Saudi family.

\section{Credibility and Consistency of the Semi-structured Question Form:}

To provide certified data, the form was submitted to the following arbitrators:

- Gihan Youssry, Professor and Dean of Faculty of Mass Communication, Cairo University.

- Samy Taya, Professor of media literacy, Faculty of Mass Communication, Ahram Canadian University.

- Amal Elgazaway, Professor of Communication, Faculty of Communication and Media, King Abdulaziz University.

- Dina Orabi, Professor of Advertising, Faculty of Mass 
Communication, Cairo University.

- Ibaa Awad, Professor of Audio Visual Media, Faculty of Communication and Media, King Abdulaziz University.

The semi-structured form was applied to $10 \%$ of the sample to make sure that the questions for the interview are clear. As for the consistency of the form, it was proven through its reapplication to the same respondents. The percentage of reliability between the two applications consistencies was $90 \%$.

\section{Findings of the Study}

\section{Awareness of media education degree:}

Figure 1. The extent of respondents' awareness of media education

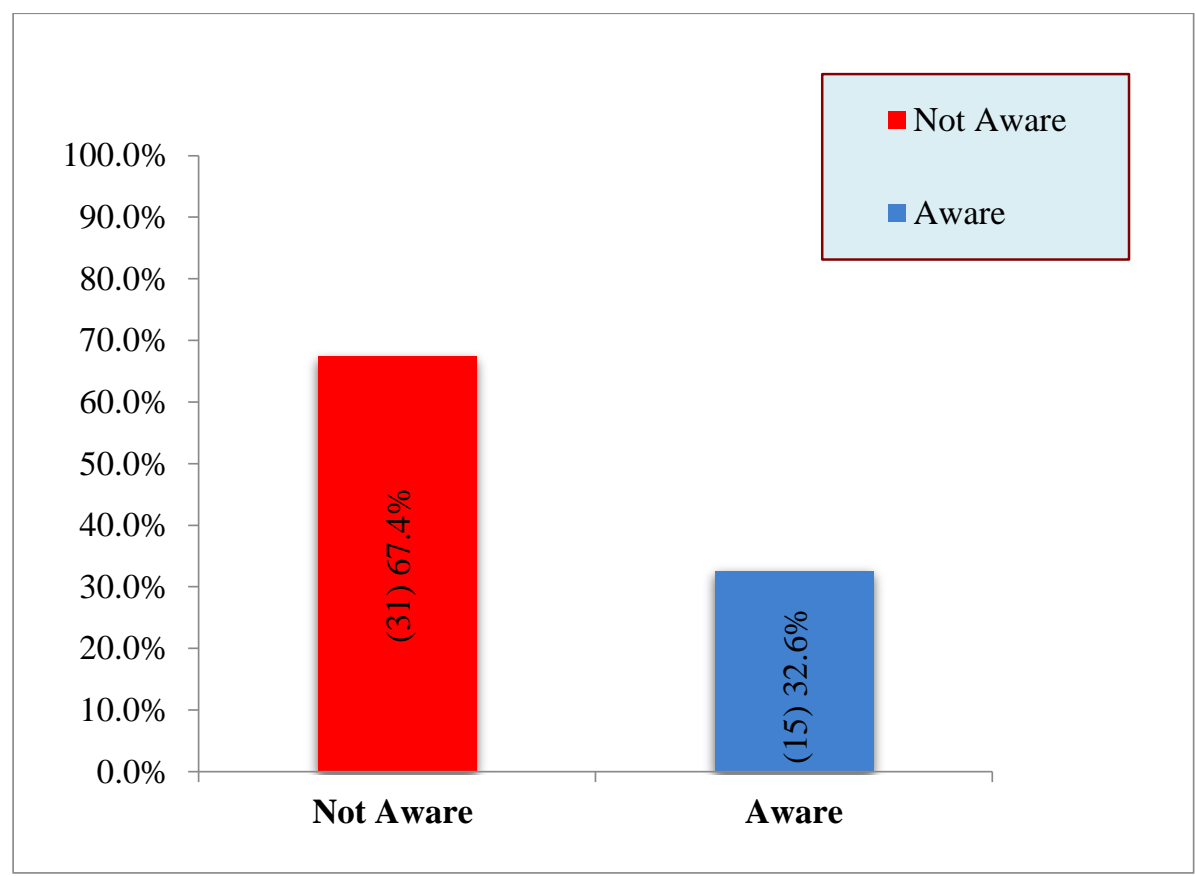

Figure 1 showed that the percentage of the respondents who were unaware of the media education was $67.4 \%$ while the percentage of those who were aware reached only $32.6 \%$. The results of the figure showed that the largest percentage of respondents had no awareness of 
this concept which reflects negatively. Media professionals should have skills consistent with community values and goals in the written policy and participation between themselves and educators (Kareem, 2003).

Figure 2. Responsibility for development of media education in the community according to media professionals

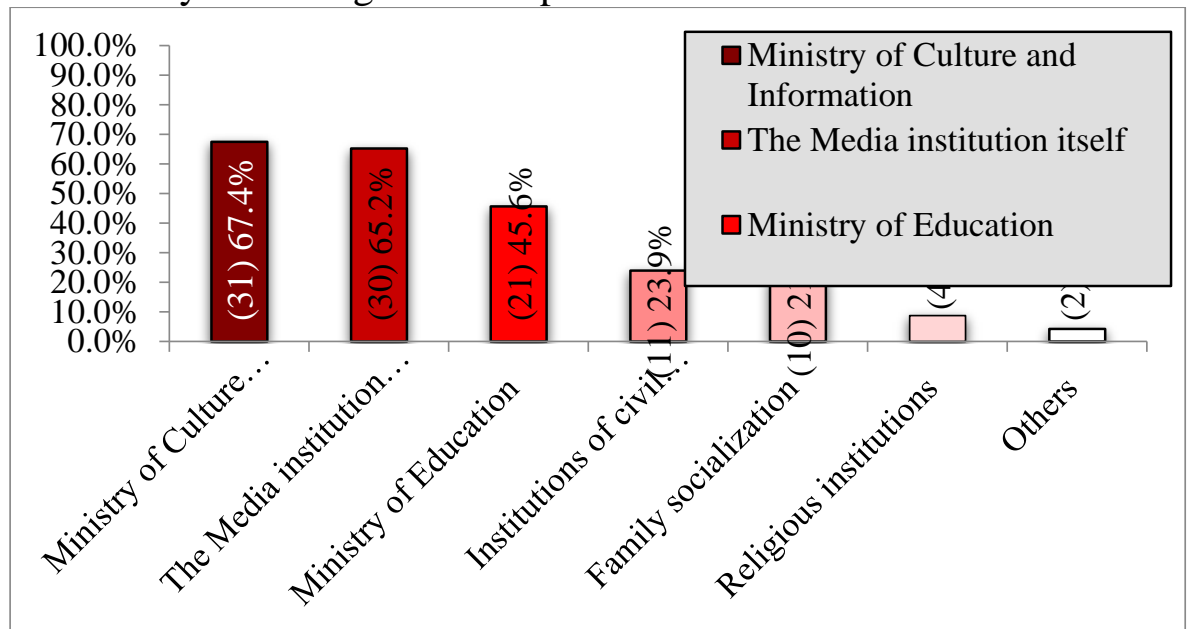

Figure 2 showed that $67.4 \%$ of the respondents believe that the responsibility for raising awareness of media education lies with the Ministry of Culture and Information. $65.2 \%$ of the respondents believe that it is on the media institutions themselves and $45.6 \%$ of the respondents report that it is on the Ministry of Education.

Figure 3. The extent to which media professionals cooperate with educators according to the sample

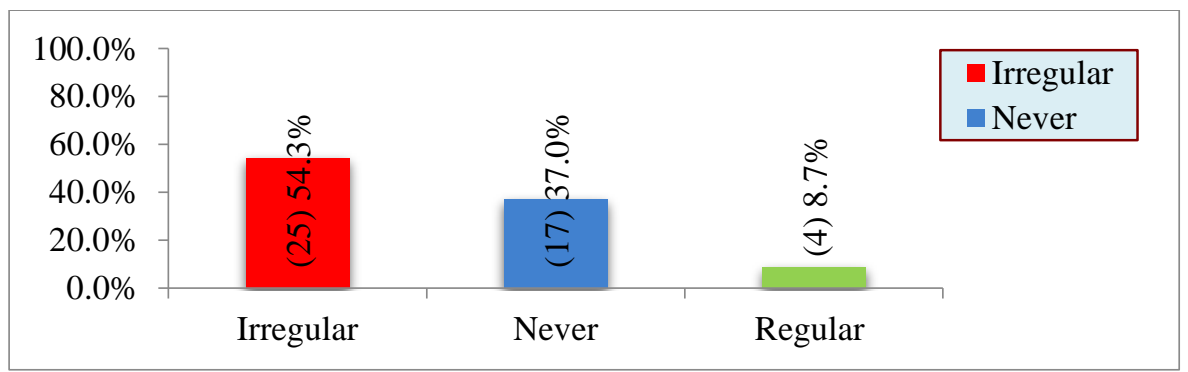


Figure 3 showed that the percentage of respondents that think there is irregular cooperation with educators in the production of programs reached $54.3 \%$. $37 \%$ of them believe that there is no collaboration with educators in production. Only $8.7 \%$ of them reported that there is regular cooperation with educators. The results are consistent with a previous study showing the extent of disagreement between Saudi media professionals and educators about the lack of cooperation between the Ministries of Culture and Information and education (Ashi, 2003).

Figure 4. The extent to which heads of media institutions are interested in applying media policies

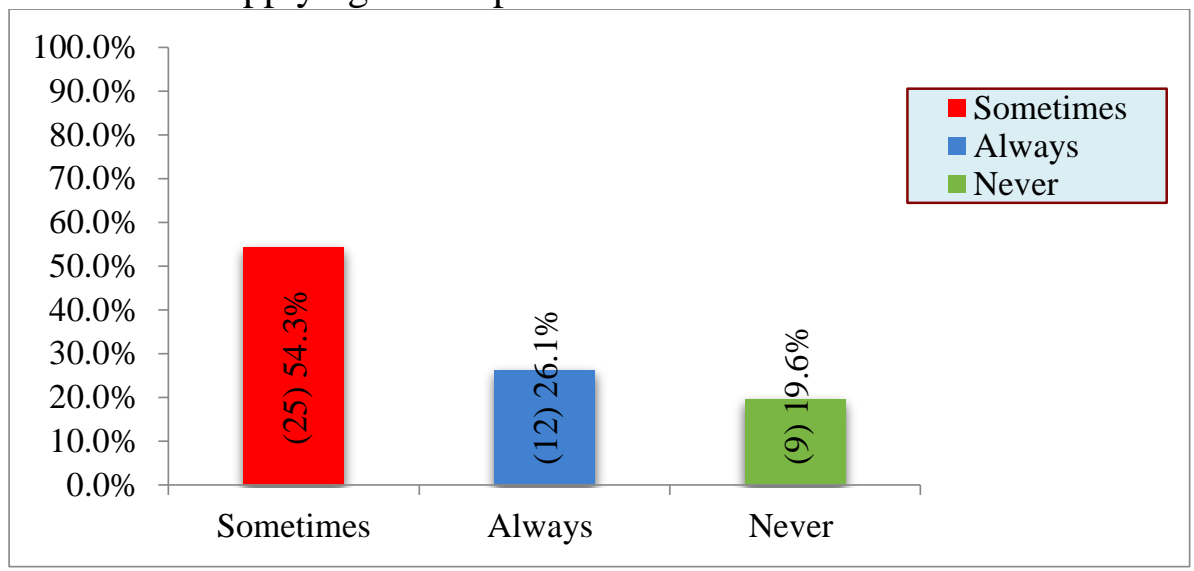

Figure 4 showed that the percentage of respondents who believe that there is sometimes a focus by presidents of the channels on the media policies reached $54.3 \%$ while the percentage of respondents who reported, "Always" reached 26.1\%. Lastly, the percentage of respondents who reported, "Never" was only $19.6 \%$, indicating shortcomings with some of the heads of the broadcasters concerning adhering to the media policies and their application. These results are consistent with a previous study showing dissatisfaction of educators regarding Saudi children's media policy and its application in practice (Ashi, 2003).

Furthermore, they are confirmed by Dennis McQuail as he stated that the main foundations of social responsibility theory lie in that media are responsible and have obligations towards the community to gain the public's trust (McQuail, 2010). 
Figure 5. The reasons for not applying the of media education in media practices

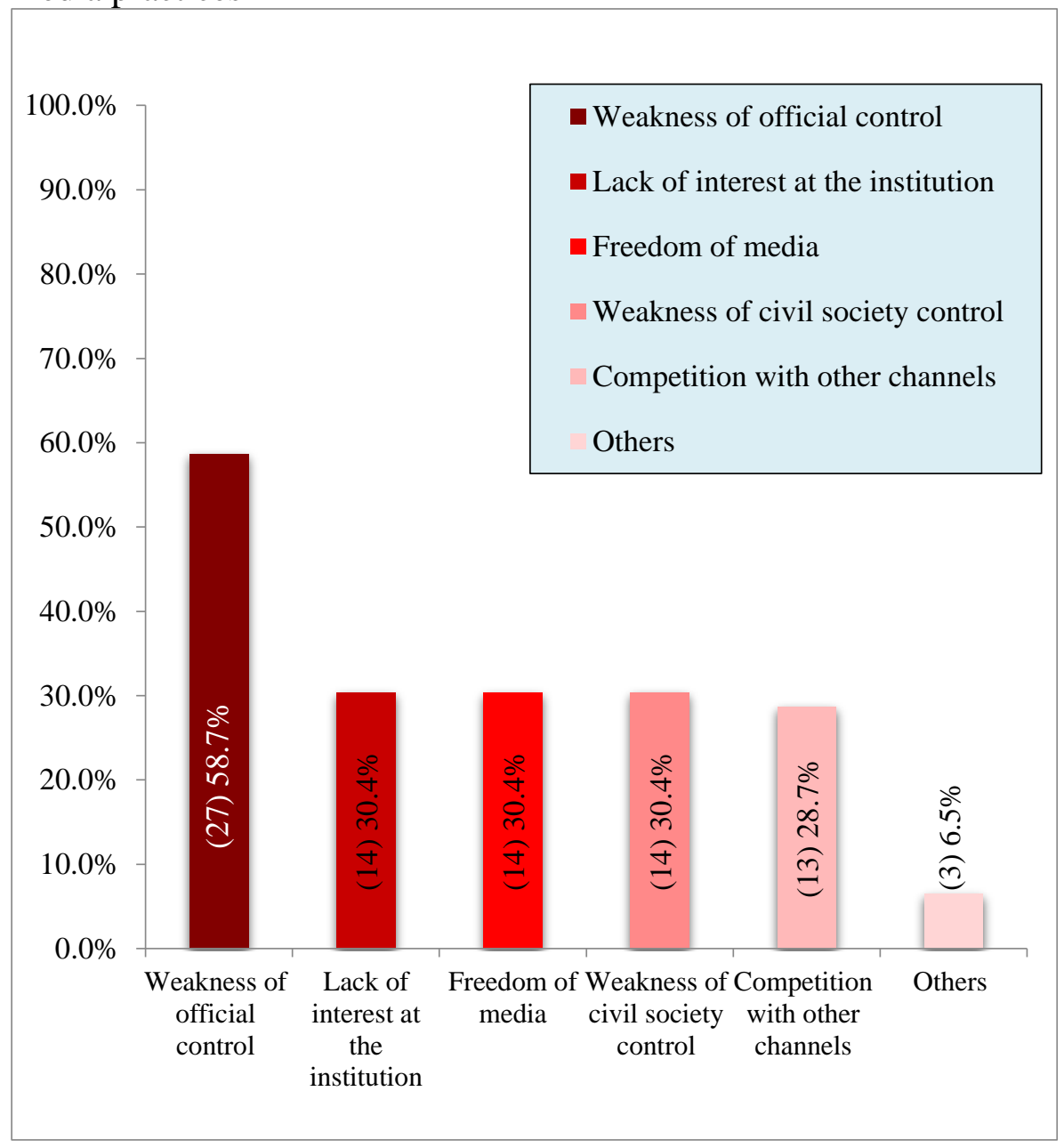

Figure 5 showed that $58.7 \%$ of respondents believed that the non-application of the media education is due to poor official oversight. Lack of interest at the institutions, poor control of civil society and calling for freedom of media were equally reported by $30.4 \%$. $28.7 \%$ of respondents saw that the non-application of it in media practices is due to the pretext of competition among media. This was emphasized by a study entitled: "Media and Political and Regional Variables" presented in the conference: "Media Today: A World without Barriers" (Shuman, 2013). 
Figure 6. Assessment of Saudi media institutions' performances according to broadcasters

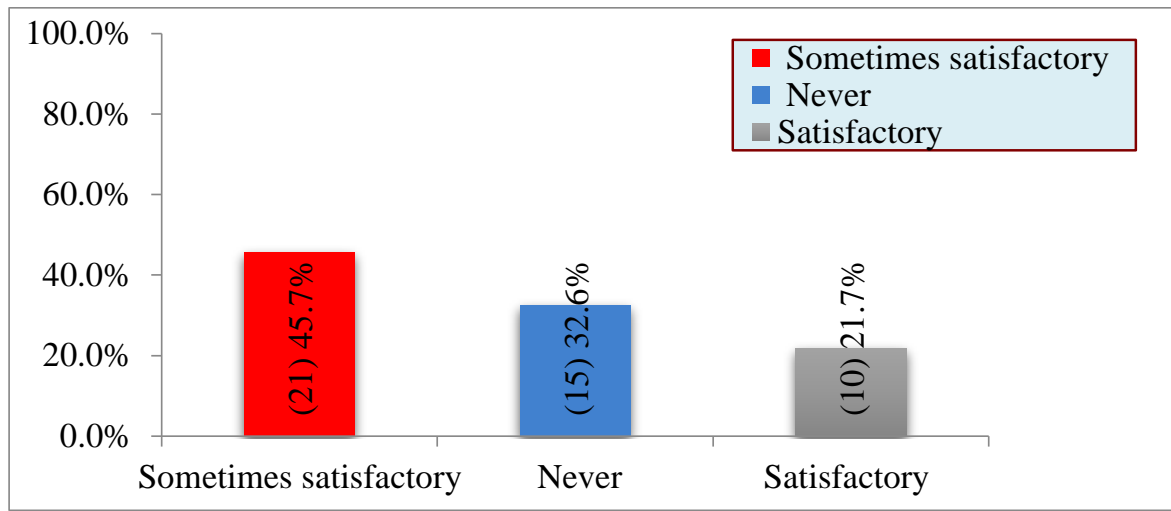

Figure 6 showed that the percent of respondents who believe that the performance of Saudi private media in commitment to the media policies is satisfactory reached only $21.7 \%$. The rest of them felt that their performance is not satisfactory at all and inconsistent despite the importance of the "media education" or media literacy (Moussa, 2010).

Figure 7. Assessment of Communicator performance

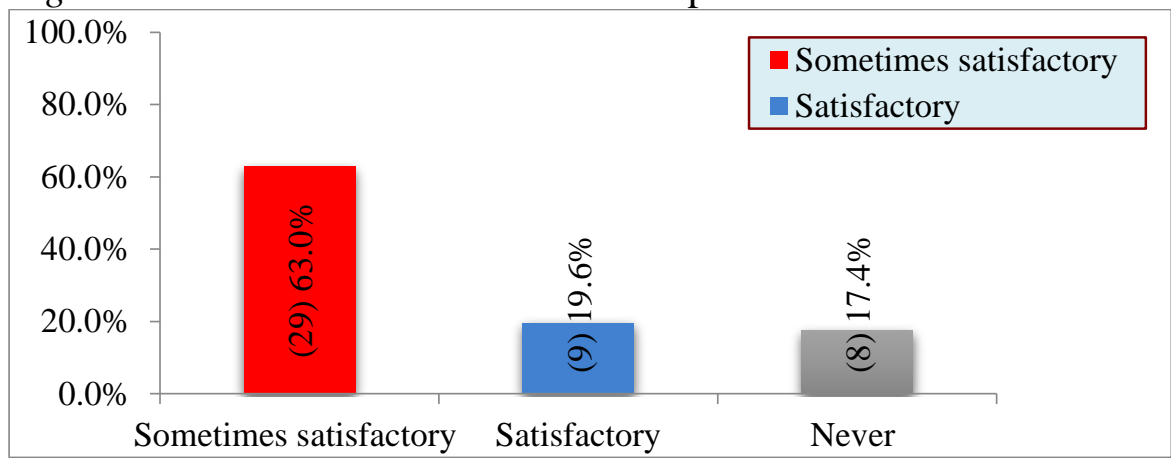

Figure 7 showed that the vast majority of the sample felt that their performance was inconstant or entirely dissatisfactory while only $19.6 \%$ of respondents think that their performance towards the family is satisfactory. This result should be an incentive for the broadcasters to evaluate their professional performance towards the community and reconsider it. 
Figure 8. Reliance on the code of conduct

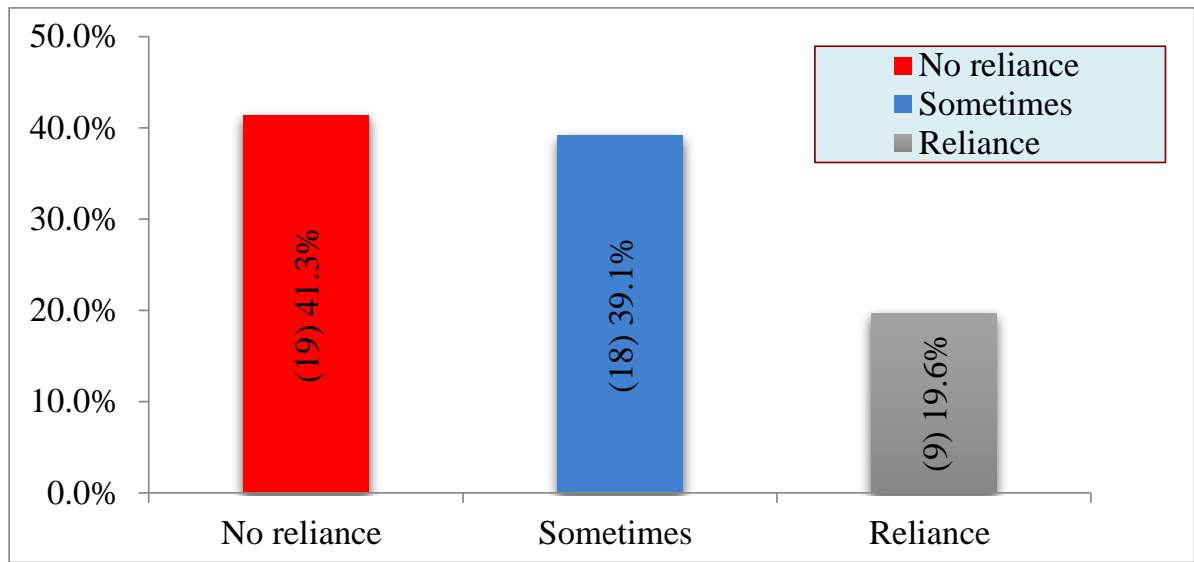

Figure 8 showed that the percentage of respondents who answered, "No" for reliance on the code of conduct in the message reached $41.3 \%$. The percentage of respondents with "Sometimes" was $39.1 \%$, and the broadcasters that answered, "Yes" were only $19.6 \%$. According to (Chen, 2007), media codes of conduct are not applied effectively. Some institutions seek commercial profits regardless of ethical or professional sides. Some studies on broadcasters indicated that regulations and media policies are not discussed with other media professionals within the organization rendering them unaware and ignorant of the policies and regulations. (Chen, 2007). 
Figure 9. Saudi families and children are exposed to the following materials in media professionals' view points

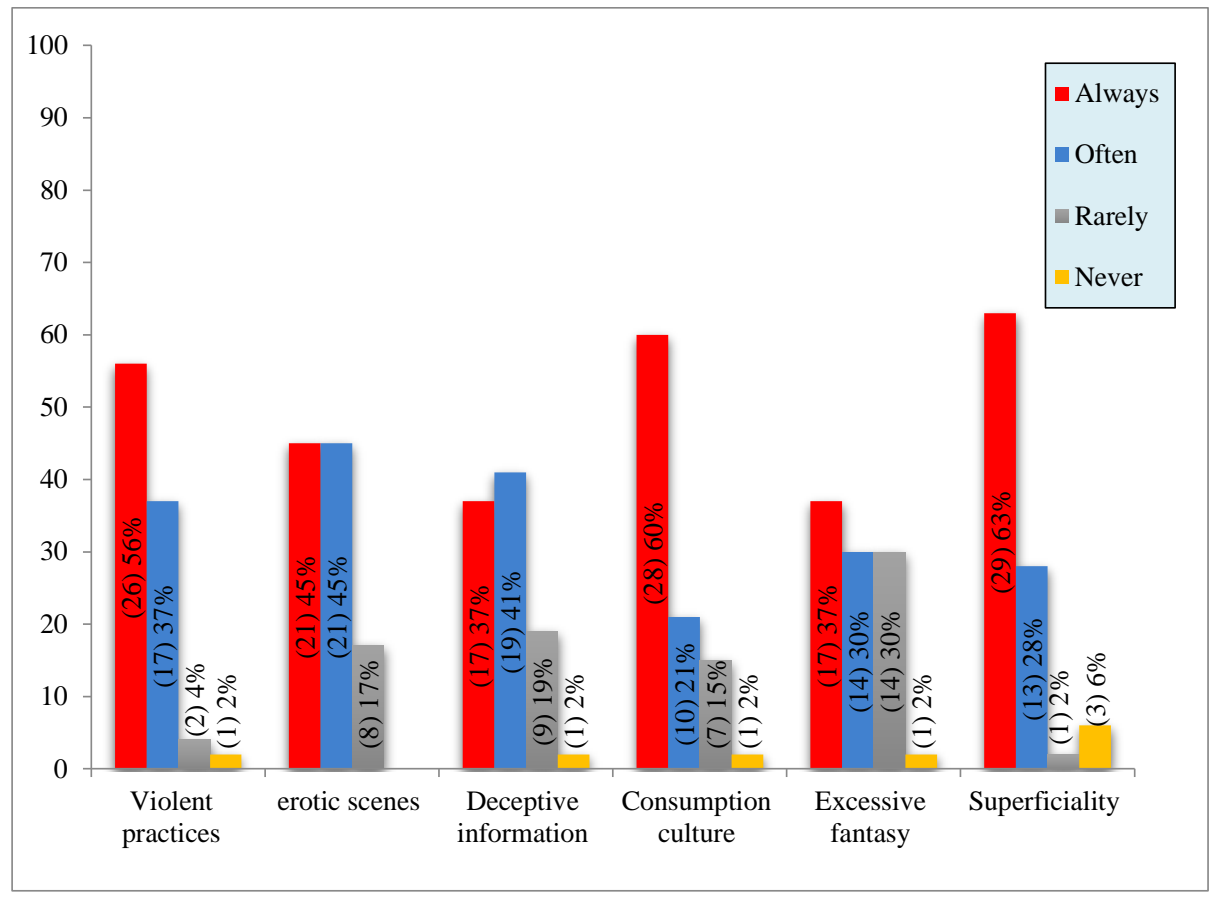

The results in Figure 9 showed that Saudi families and children, from media professionals' view points are often exposed to materials about violence, superficiality, erotic scenes, consumption, deceptive information and excessive fantasy. These figures reached $93.5 \%, 91.3 \% \%, 82.7 \%, 82.6 \%, 78.3 \%$ and $67.4 \%$, respectively. This is confirmed by a study which showed that 14 crimes were committed per hour as a result of watching violent media programs (Martins \& Wilson, 2012). 
Figure 10. Opinions of Broadcasters on censorship of media materials in Saudi Arabia

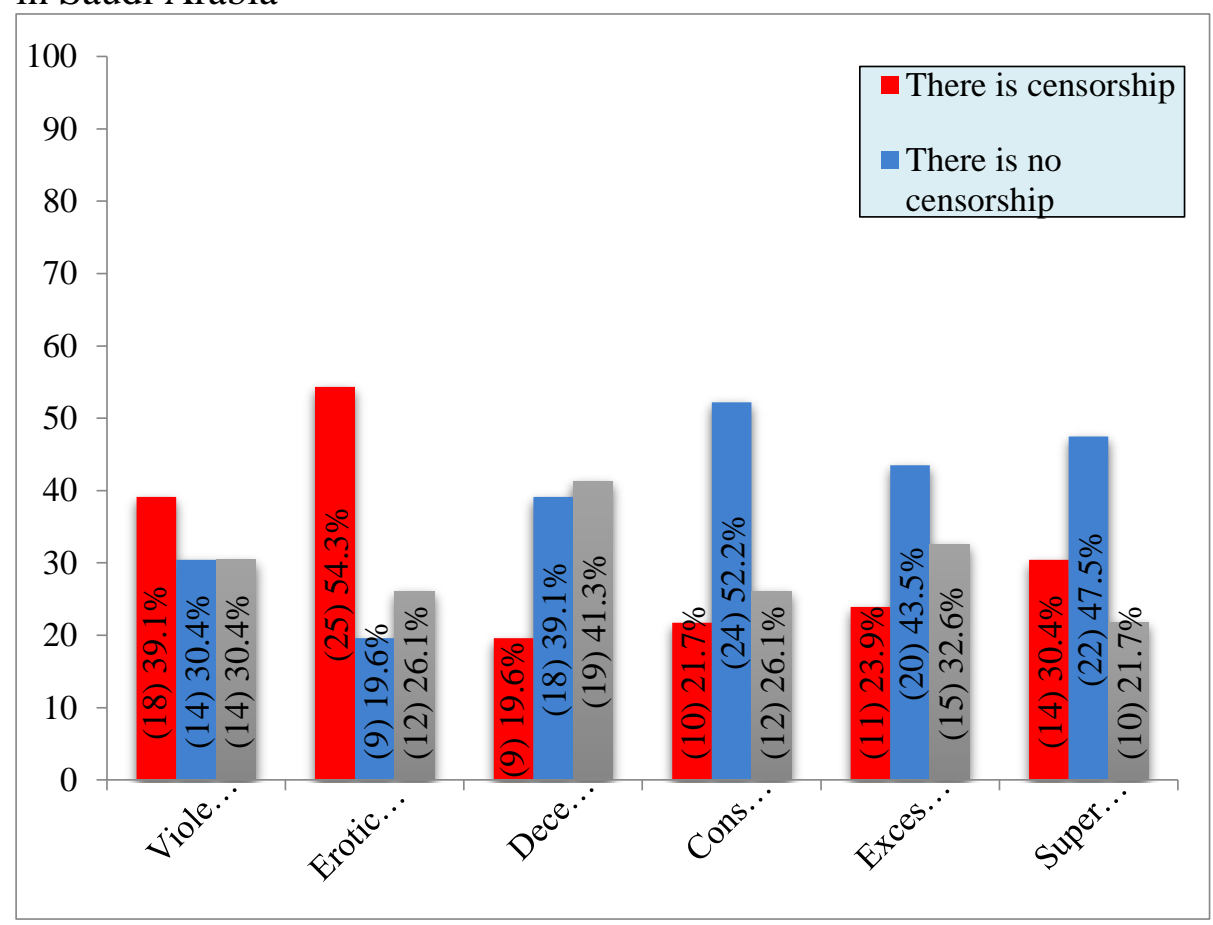

Figure 10 indicates that there is weak control over media materials displayed to families. The percentages of "Sometimes" and, "There is no censorship" to deceptive information was $80.4 \%$, consumption culture was $78.3 \%$, excessive fantasy reached $76.1 \%$, $69.5 \%$ for superficiality and $60.8 \%$ for violent practices, respectively. These results confirm negligence of media institutions in protecting families and society from negative values in media materials. Some results of previous studies on Arab and foreign series confirmed negative values embodied in them, particularly foreign series (Al Ghazzawi, 2008). These findings confirm the importance of media education and its application. 
Figure 11. Communication of media professionals with society

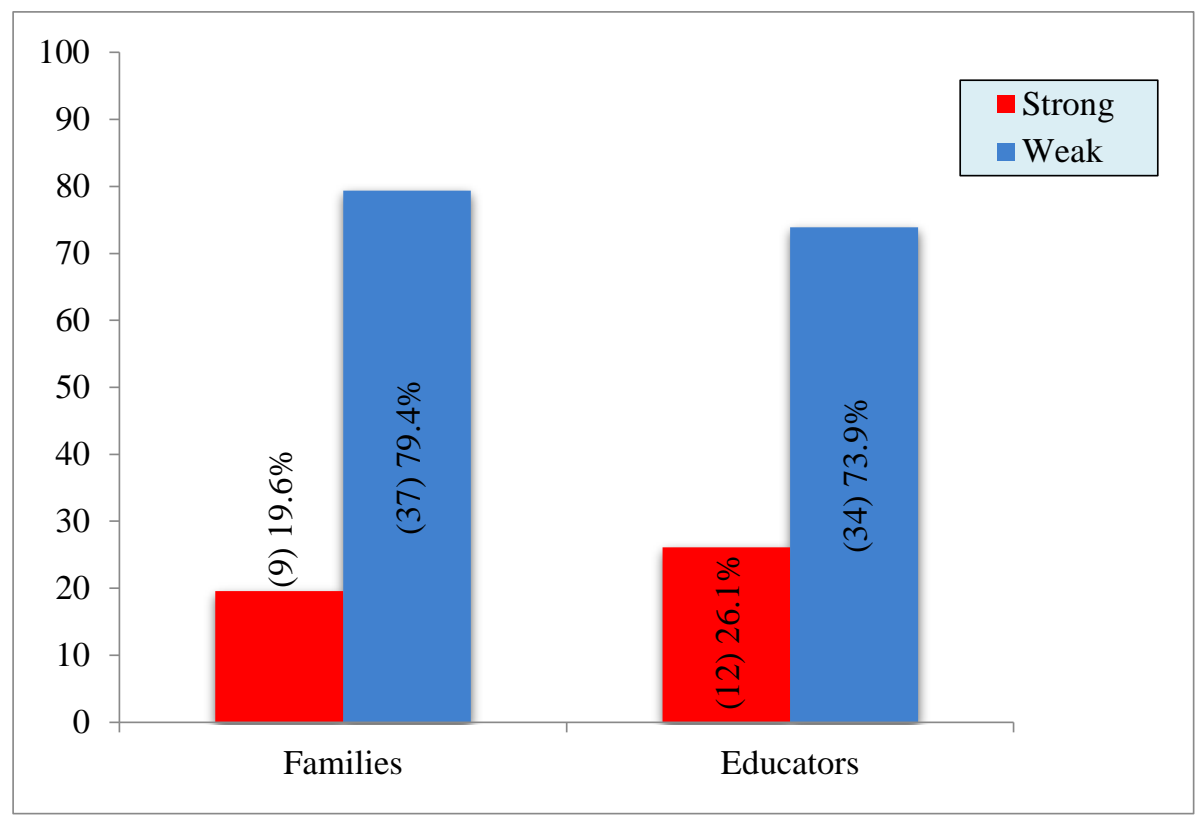

Figure 11 showed that media professionals admitted that their contact with the community is very weak. The majority of the broadcasters had substandard contact with families and educators with rates at $80.4 \%$ and $73.9 \%$, respectively. The gap of communication between broadcasters from one side and families and educators from the other allowed for the irresponsible media practices.

Proposals for media performance improvement in relation to media education according to broadcasters:

To reach effective proposals, answers to open-ended questions were introduced as follows: 
Vision of Broadcasters Towards the Role of Media Education and ethics in Saudi Arabia

Figure 12. Proposals on ways to combat misleading messages

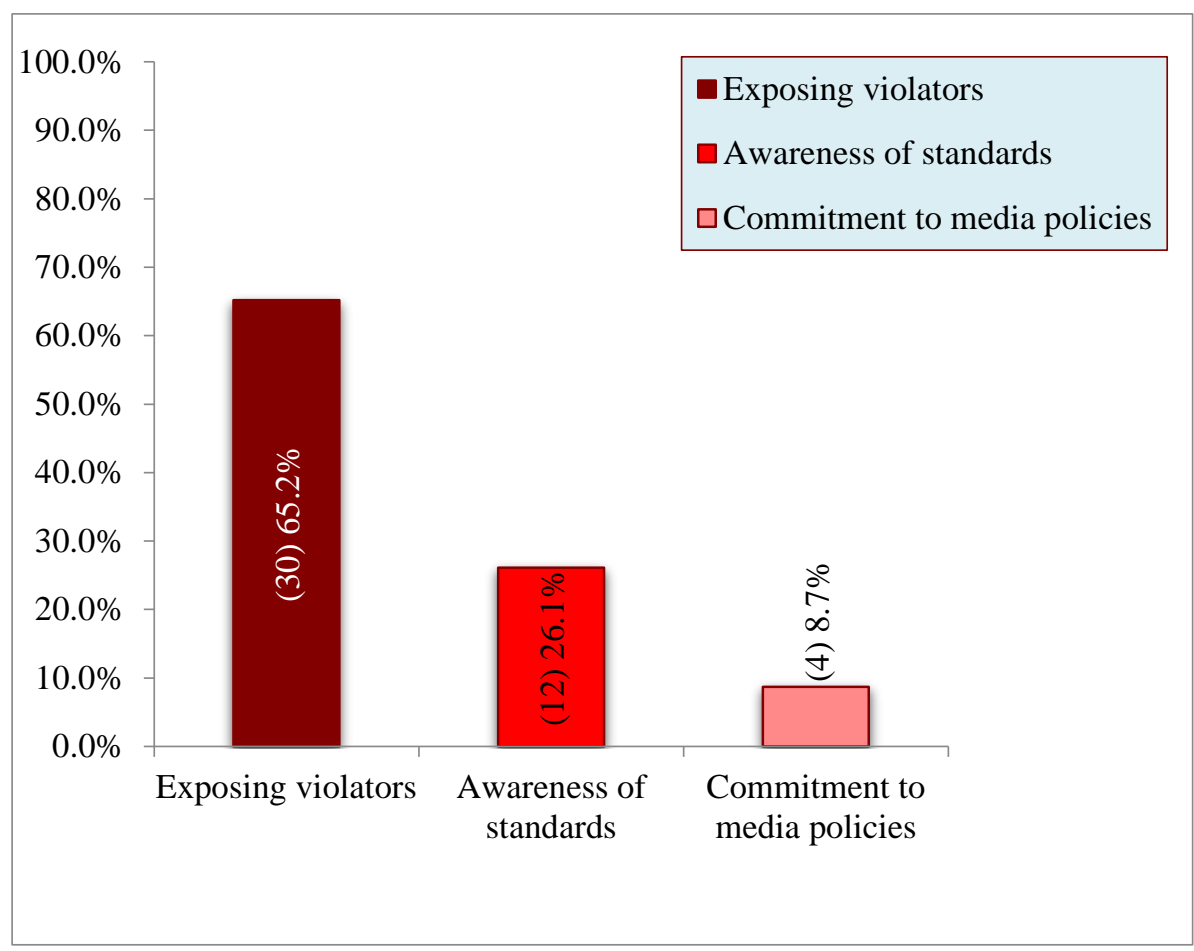

Figure 12 shows that $65.2 \%$ of respondents felt the need to expose the misleading messages. This could be a result of their recognition and their understanding of the amount of

misleading media materials and their danger to society. 
Figure 13. Important criteria to be included in the media message

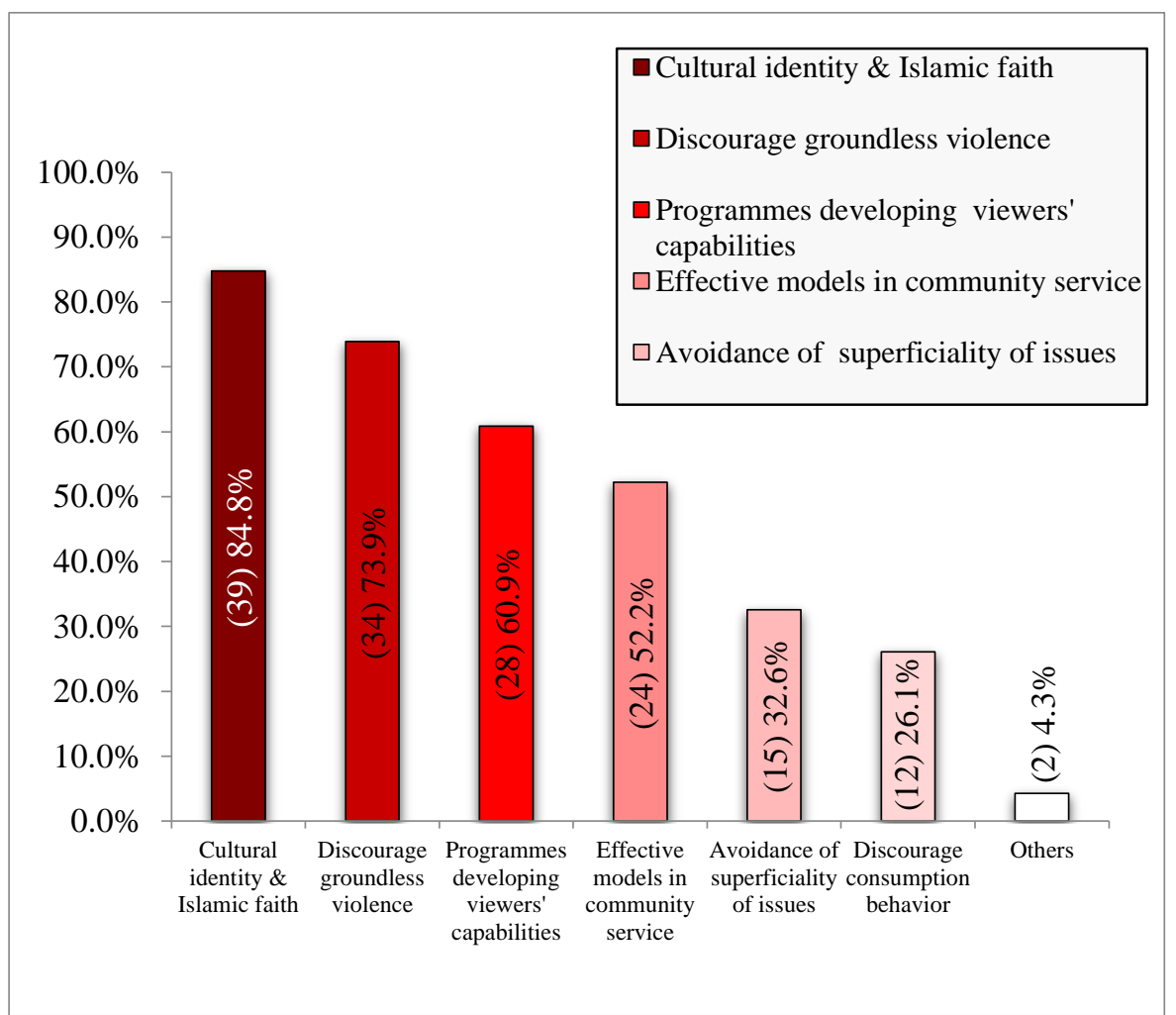

Figure 13 showed that $84.8 \%$ of respondents consider the national Islamic identity as one of an important criteria that must be included in the media message. $73.9 \%$ of the sample said that excessive violence should not be provided. $60.9 \%$ of them suggested the need to view programs to develop the capacity of spectators and $52.2 \%$ referred to the need to focus on active models in the community. This result confirms that the media message is devoid of the simplest positive values that the society needs. 
Figure 14. Proposals for penalties for violation of the media ethical code of conduct

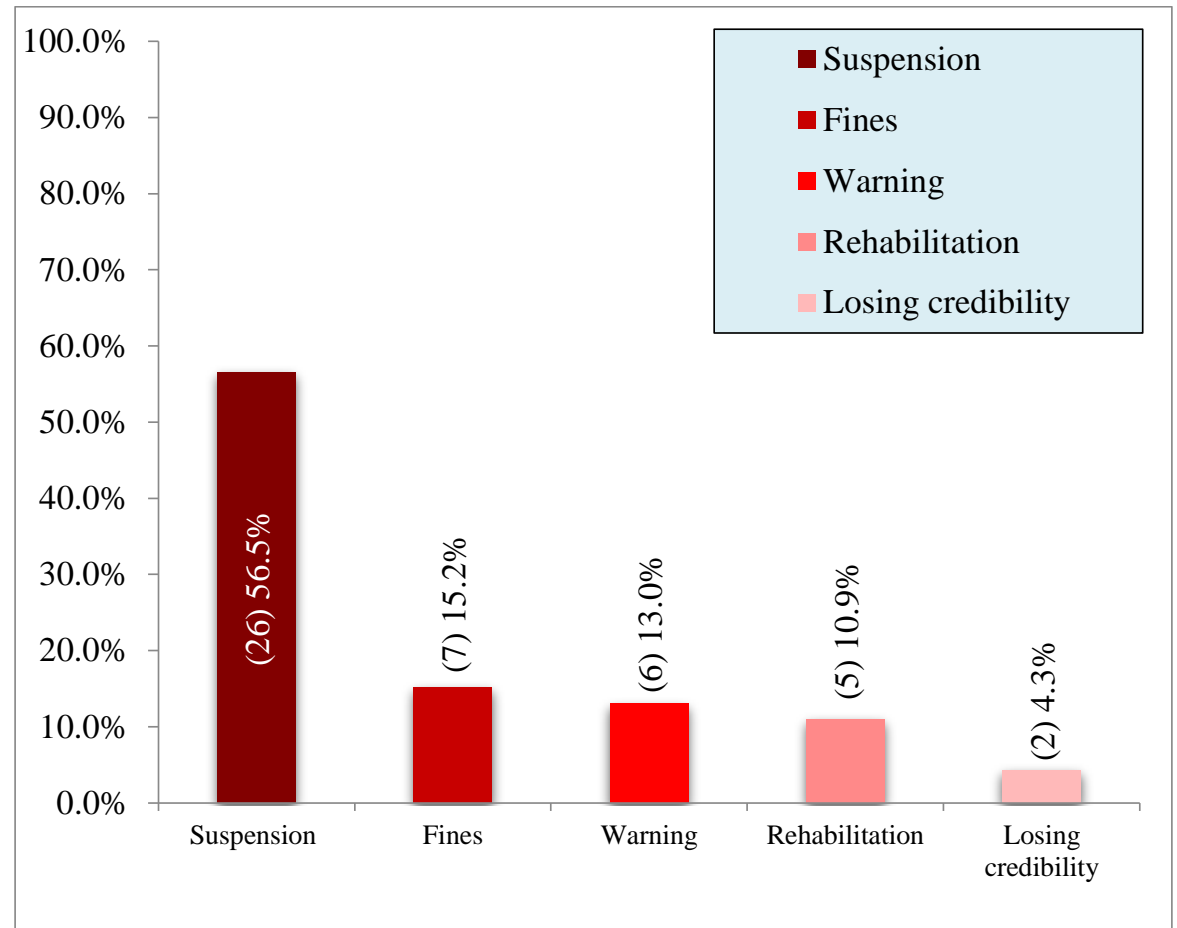

Figure 14 showed that $56.5 \%$ of respondents proposed suspension for the media professional who breaches the media message ethics and it is the largest proportion, which refers to the need to apply the reward and punishment principle to be a deterrent to anyone who doesn't adhere to the ethical codes of conduct.

Figure 15. The broadcasters' views regarding methods to improve media performance 


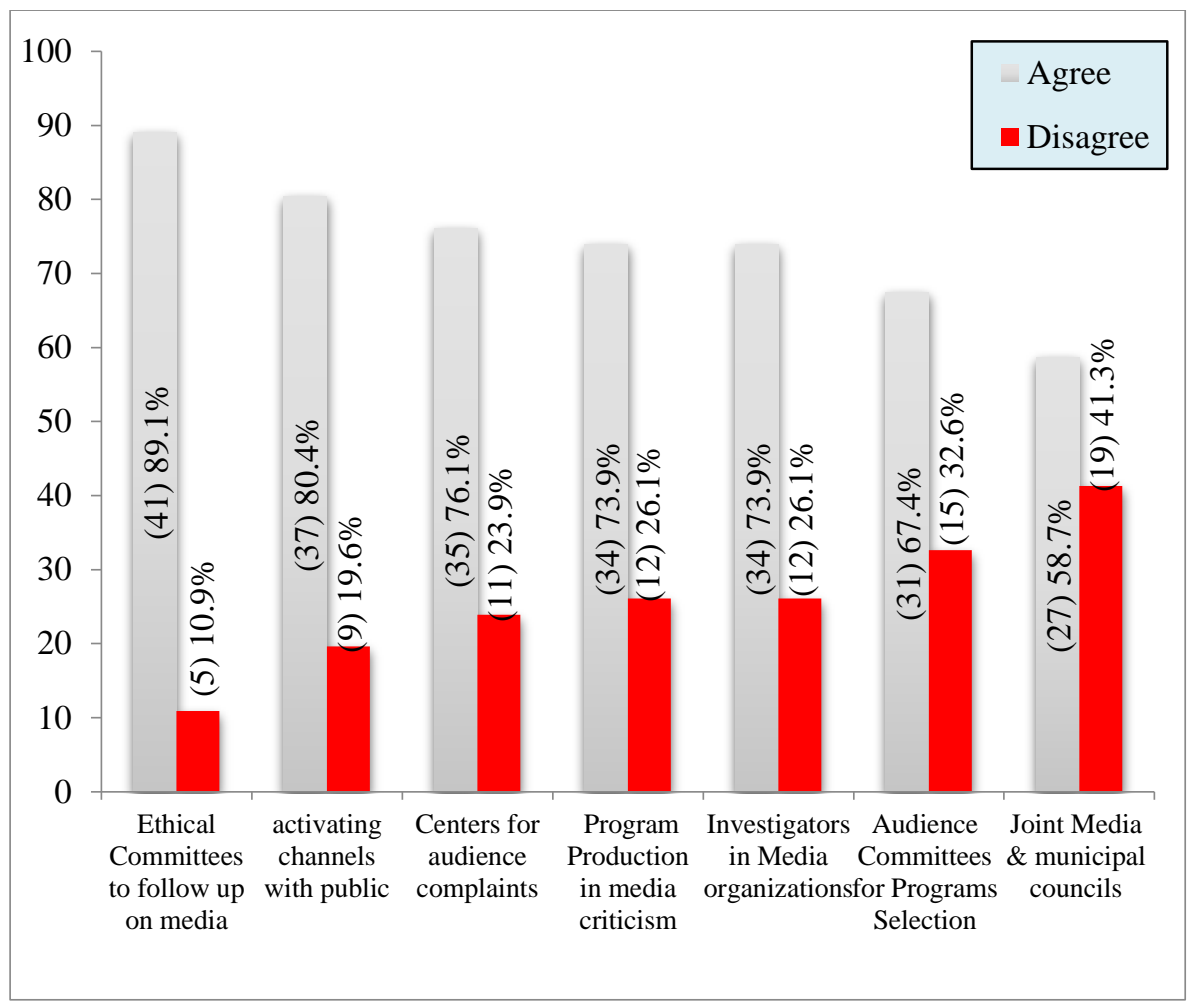

Figure 15 showed that respondents believe that there are effective methods to improve media performance and theyare: to form an ethics committee. The figures favoring this reached $89.1 \%$. The percentage of those who consider activating channels with the public reached $80.4 \%$. Those who supported the establishment of offices for complaints was $76.1 \%$. The need to produce specialized programs in media criticism and appointment of investigators in the media foundations got the same percentage of $73.9 \%$ each. The percentage of those who called for the formation of audience committees for programs selection reached $67.4 \%$ and the respondents who felt the need to hold joint media councils and municipal councils were $58.7 \%$. This result confirms the negligence of media ethical codes of conduct among media professionals. Serious steps need to be established to implement media education for media professionals.

\section{Conclusion}

In this study, the majority of respondents had no awareness of 
the concept of media education, despite the call by UNESCO to its importance. Most of the respondents felt that the responsibility for raising awareness of media education should be on the Ministry of Culture and Information in the first place, then on the media foundation itself and Ministry of Education. Cooperation between media professionals and educators seemed to be marginal, nonbinding and has no clear goals or strategies. The broadcasters consider that the performance of Saudi media is dissatisfactory and modest. All in all the broadcasters indicate that they are not satisfied with their performance towards the family and children, especially under Muslim Arab society ethics. Broadcasters admit to the negative effect of the media materials on children and families' behavior. Broadcasters see that the cultural identity and the Islamic faith are important criteria that must be included in the media message and they also feel that they have to play a great role to fight misleading messages. Respondents agreed that the effective method to improve the media performance is by the formation of ethics committees, activation of channels with the public, and the establishment of complaints offices. Respondents suggested suspension from work as a penalty for violators of media codes of conduct.

\section{Recommendations}

- Media and educational institutions should pay attention to media education and should rehabilitate and empower their media professionals because of its utmost importance as part of the basic rights of citizens.

- Clear strategies must be developed by relevant ministries to contribute to media education.

- Encouraging research and studies in the areas of media, education, planning and community service.

- Focusing on family and school should be a target of media education for intellectual immunity.

- Commitment to media policies derived from Saudi values and ethics of the Arab-Muslim community.

- Holding joint meetings between media councils and municipal councils in addition to screening.

- Activating channels so that the audience can express their views as well as establishment of offices for complaints. 


\section{References}

Abdul Halim, S. (2012). Social Responsibility of the Egyptian Satellite Governmental and Private Channels as seen by the Elite: Field and Analytical study. Unpublished MA. Cairo University: Faculty of Mass Communication.

Al Abbasi, A. (2003). Egyptian Newspapers Journalists' Vision of the Ethics of Professional Practice. the Ninth Annual Scientific Conference of the Faculty of Mass Communication: "Media Ethics between Theory and Practice". Cairo, Egypt: Cairo University.

Al Ali, F. (2008). The Role of Communicator in TV Talk Shows Responsibility towards Society in the UAE. the Fourteenth Annual Scientific Conference of the Faculty of Mass Communication: "Media between Freedom and Responsibility. Cairo, Egypt: Cairo University.

Al Banna, H. (2008). Media Ethics in Private Arabic Satellite Channels as Seen by the Egyptian public. the Fourteenth Annual Scientific Conference of the Faculty of Mass Communication: Media between Freedom and Responsibility. Cairo, Egypt: Cairo University.

Al Ghazzawi, A. (2008). Uses of Arabic Women to the dubbed Series and the Satisfactions achieved from them: An Empirical Study. Egyptian Journal of Media Research, XXXII, 26.

Al Kahki, A. (2008). The Limits of Freedom and Responsibility as Seen by Al-Jazeera Communicator. the Fourteenth Annual Scientific Conference of the Faculty of Mass Communication: "Media between Freedom and Responsibility". Cairo, Egypt: Cairo University.

Al Musaind, A. (2012). Uses and Satisfactions of Saudi Media Professionals to New Social Media in Riyadh City. MA. Riyadh: King Saud University.

Al Nemr, A. (2008). The Chat Bar on Arabic Satellite channels between Ethics and Professional Responsibility. the Fourteenth Annual Scientific Conference of the Faculty of Mass Communication: "Media between Freedom and Responsibility". Cairo, Egypt: Cairo University.

Al Shimemeri, F. (2010). Media education: How do we deal with the Media? Riyadh.

Al Subaihi, M. b. (2008). The Functional Relationship between the Communicator and the Public: A Descriptive Study in the light of Modern Communications Environment Variables in Saudi Arabia. Unpublished PhD Thesis. Islamic University of Imam Muhammad Bin Saud.

Ananya, B. (2011). Is Nation's Watchdog Really Peeping into The Nation? Global Media Journal: Indian Edition, Summer Issue, June 2011.

Ashi, H. (2003). Saudi Children Viewing Interests in the Age of Globalization: A Case Study in Jeddah. Unpublished PhD Thesis. University of Leicester.

Ashi, H. (2018) the Role of the Family in the Application of Media Education in the Shade of the 2030 Vision of the Kingdom of Saudi Arabia..Arab Journal of Media \& Communication Research, (22), 2018.

Baran, S. J., \& Davis, D. K. (2011). Mass Communication Theory: Foundations, Ferment, and 
Future. In Wadsworth Series in Mass Communication and Journalism (6th ed.). Cengage Learning.

Basu, S. (2011). Social Responsibility: The Obligation of Mass Media. Global Media Journal: Indian Edition, Summer Issue, June 2011.

Chakroff, J. (2008). Mitigating the Unintended Effects of Advertising on Young Children: The Effectiveness of Parent-Administered Active Mediation. the Annual Conference of the International Communication Association. Montreal, Canada.

Chen, G.-M. (2007). Media (Literacy) Education in the United States. China Media Research, $3(3), 87-103$

Christ, W., \& Potter, W. (1998). Media Literacy, Media Education, and the Academy. Journal of Communication, 48(1), 5-15.

Cleary, J., \& Adams-Bloom, T. (2009). The Family Business: Entertainment Products and the Network Morning News Shows. Mass Communication \& Society, 12(1).

Corneo, G. (2005). Media Capture in a Democracy: The Role of Wealth Concentration. Retrieved from CESifo Working Paper Series No. 1402: https://papers.ssrn.com/sol3/papers.cfm?abstract_id=667326

Feenstra, R., \& Esteban, E. G. (2017). Autocontrol: A Critical Study of Achievements and Challenges in the Pursuit of Ethical Advertising Through an Advertising SelfRegulation System. Journal of Business Ethics, 1-14.

Gomaa, O. (2007). The Impact of Freedom of the Press in Egypt on Professional Practice: A Study on the Content and Communicator during 2004 and 2005. Unpublished MA. Cairo University, Faculty of Mass Communication.

Hassan, A. (2008). The Limits of Freedom and Professional Responsibility in The Performance of Global Satellite News Networks and their Impact on the Direction of Foreign Audience about Arabic Issues: An Empirical Comparative Study. the Fourteenth Annual Scientific Conference of the Faculty of Mass Communication: "Media between Freedom and Responsibility". Cairo, Egypt: Cairo University.

Hobbs, R. (2011). The State of Media Literacy: A Response to Potter. Journal of Broadcasting and Electronic Media, 55(3), 428-553.

Hollon, L. (2009). The National Conference on Media Reform. Media Development, 56(1).

Ibrahim, M. (2003). The Ethical and Legal Responsibilities of Journalists and their Relationship with Personality Traits. the Ninth Annual Scientific Conference of the Faculty of Mass Communication: "Media Ethics between Theory and Practice". Cairo, Egypt: Cairo University.

Ibrahim, M. (2011). Media for development and pluralis. Cairo, Egypt: Dar Al- Kutub AlIlmia for Publishing and Distribution.

khalifa, s. (2015) Media Elite's Tendency Toward News Sites' Commitment of Work Ethics Unpublished MA. Gaza: Faculty of Arts, Islamic University.

Kareem, B. (2003). Media Education. the Press and Education Conference. Mecca.

Khedr, N. (2008). Trends of the Communicator toward the concepts of Freedom and Social Responsibility of the Press in Egypt in the Third Millennium. the Fourteenth 
Annual Scientific Conference of the Faculty of Mass Communication: "Media between Freedom and Responsibility". Cairo, Egypt: Cairo University.

Martins, N., \& Wilson, B. J. (2012). Mean on the Screen: Social Aggression in Programs Popular With Children. Journal of Communication, 62(6), 991-1009.

McQuail, D. (2010). Mass Communication Theory (6th ed.). London: Sage.

Mekawy, E., \& Al-Sayed, L. (2011). Communication \& Contemporary Theories. Cairo: Egyptian Lebanese House.

Middleton, M. (2011). Social Responsibility in the Media. Retrieved from Global Media Journal: Indian Edition: http://www.caluniv.ac.in/global-mdiajournal/DOCOUMENT/Document\%206.pdf

Mohammadain, A. (2002). The Constraints of Professional Practice for the Broadcasters in Environmental Journalism Field. Egyptian Journal of Media Research(17).

Moussa, S. (2010). Why Media Education? Retrieved from http://naqed.info/forums/index.php?showtopic=140\&mode=threaded

Musa, B. A., \& Domatob, J. K. (2007). Who is a Development Journalist? Perspectives on Media Ethics and Professionalism in Post-Colonial Societies. Journal of Mass Media Ethics, 22(4), 315-331.

Nordenson, B. (2008). Overload. Columbia Journalism Review, 47(4).

Ortiz, M. A., Ruiz, J. A., \& Diaz, E. (2013). Are Spanish TV Broadcasters Interested in a Better TV for Children? TV Broadcasters and Research on TV and Children. Communicar, 20(40), 137-144.

Osazee-Odia, O. U., \& Ijeh, P. (2017). Studing the Pluralization of Broadcasting in Nigeria: from Perspectives to Practice. Academic Research International, 8(3), 186-203.

Perkins, M. (2002). International law and Search for Universal Principles in Journalism Ethics. Journal of Mass Media Ethics, 17(3), 193-208.

Potter, W. (2010). The State of Media Literacy. Journal of Broadcasting \& Electronic Media, 54(4), 544-675.

Reda, H. (2001). The TV Cartoon and Children's Attitudes towards Violence. Unpublished MA. Cairo: Faculty of Mass Communication, Cairo University.

Retief, J. (2002). Media Ethics: An Introduction to Responsible Journalism. Oxford: University Press.

Samir, A. (2008). The Political Influence of Egyptian and Arabic Private Satellite Channels under Social Responsibility. the Fourteenth Annual Scientific Conference of the Faculty of Mass Communication: "Media between Freedom and Responsibility". Cairo, Egypt: Cairo University.

San Román, J. A., \& Montero, M. S. (2008). TV Channels Social Responsibility: SelfRegulation on TV Contents during Special Protected Schedule. Communicar, 15(30), 113-117.

Shahin, H. (2003). Ethics News Work from the Perspective of the Broadcasters. the Ninth Annual Scientific Conference of the Faculty of Mass Communication: "Media Ethics between Theory and Practice". Cairo, Egypt: Cairo University. 
Vision of Broadcasters Towards the Role of Media Education and ethics in Saudi Arabia

Shuman, M. (2013). Media and Political and Regional Variables. the Conference of Today's Media: A World Without Barriers. Governorate of Ghat, Saudi Arabia.

Singer, J. B. (2006). The Socially Responsible Existentialist. Journalism Studies, 7(1), 2-18.

Umran, U. (2003). Obstacles to the Performance of Professional Reporter: A Field Study on the Local Correspondents in Upper Egypt. Egyptian Journal of Media Research(19).

Wu, H. D., \& Lambert, C. A. (2016). Impediments to Journalistic Ethics: How Taiwan's Media Market Obstructs News Professional Practice. Journal of Media Ethics, 31(1), 35-50.

ZDF. (2006). ZDF Facts and Figures. Retrieved from https://www.zdf.de/zdfunternehmen/factsandfigures-100.html 